\title{
Silica based aerogel-like materials obtained by quick microwave drying
}

\section{Silika basierende Aerogel-Materialien mittels schneller Mikrowellen-Trocknung erzeugt}

\author{
L. Durães ${ }^{1}$, T. Matias $^{1}$, R. Patrício ${ }^{2}$, A. Portugal ${ }^{1}$
}

\begin{abstract}
Aerogel-like silica based materials were obtained by microwave drying of the gels synthesized with methyltrimethoxysilane (MTMS) precursor. The microwave drying is an alternative ambient pressure drying technique for these nanostructured materials that allows a fast fine drying stage and avoids the high temperature cycles of conventional evaporative drying. The gels were synthesized by a two-step acid-base catalyzed sol-gel process following the procedures described in an earlier work. After 2 days of aging, they were placed in an oven at $60^{\circ} \mathrm{C}$, during one day, and then washed with distilled water at $40^{\circ} \mathrm{C}$. Finally, the gels were dried in a microwave oven, at $450 \mathrm{~W}$, in three cycles of two minutes each with two minutes of interval. During drying, a reduction of the gel volume was observed, but the major part of this volume was recovered by spring-back effect in 2 days, giving aerogel-like materials with a density in the interval $60-80 \mathrm{~kg} / \mathrm{m}^{3}$. The final materials are monolithic, flexible and have a thermal conductivity of $\sim 0.04 \mathrm{~W} /(\mathrm{m} \mathrm{K})$, which make them suitable for insulation applications. Additionally, they exhibit high hydrophobicity (contact angle $\sim 150^{\circ}$ ) and surface area $\left(414 \mathrm{~m}^{2} / \mathrm{g}\right.$ ), what can be beneficial for adsorption of some organic pollutants.
\end{abstract}

Keywords: sol-gel / silica / nanostructured materials / drying / microwaves

Aerogelartiges Silika basierte Materialien wurden durch Mikrowellen-Trocknung des Gels, syntetisiert aus Methyltrimethoxysilan Ausgangsstoff, hergestellt. Die Mikrowellen-Trocknung ist ein alternatives Trockenverfahrem bei Umgebungsdruck für solche nanotrukturierten Materialien, die eine schnelle Trocknung erlauben, und vermeidet hohe Temperaturzyklen wie beim konventionellen Verdampfungstrocknen. Die Gels wurden in einem säurebasierenden Sol-Gel Zweistufenprozess synthetisiert, der in einer früheren Arbeit beschrieben wurde. Nach einem zweitägigen Alterungsprozess wurden die Gels in einem Ofen bei $60^{\circ} \mathrm{C}$ für einen Tag gelagert und anschließend mit destilliertem Wasser bei $40^{\circ} \mathrm{C}$ gewaschen. Schließlich wurden die Gels in einem Mikrowellenofen bei $450 \mathrm{~W}$ in drei Zyklen getrocknet, wobei jeder Zyklus zwei Minuten dauerte mit Intervallen von zwei Minuten. Während der Trocknung wurde eine Abnahme des Gelvolumens beobachtet, jedoch konnte der größte Teil dieses Volumens innerhalb von zwei Tagen durch einen ,Rückfederungseffekt' wiedergewonnen werden, so dass ein areogelartiges Material mit einer Dichte im Intervall von $60-80 \mathrm{~kg} / \mathrm{m}^{3}$ erhalten wurde. Das endgültige Material ist monolithisch, flexibel und besitzt eine Wärmeleitfähigkeit von $\sim 0.04 \mathrm{~W} /(\mathrm{m} \mathrm{K})$, so dass ein Einsatz als Isolator sinnvoll erscheint. Darüber hinaus weisen sie eine hohe Hydrophobie (Kontaktwinkel $\sim 150^{\circ}$ ) und Oberfläche $\left(414 \mathrm{~m}^{2} / \mathrm{g}\right)$ auf, was von Vorteil sein kann für die Adsorption von einigen organischen Schadstoffen.

Schlüsselwörter: Sol-Gel / Silika / nanostrukturierte Materialien / Trocknung / Mikrowellen

\section{Introduction}

Silica based materials synthesized by sol-gel technology from methyltrimethoxysilane (MTMS) precursor have very interesting and unique properties, especially for thermal/electric/acoustic

\footnotetext{
${ }^{1}$ CIEPQPF, Department of Chemical Engineering, Faculty of Sciences and Technology, University of Coimbra, Pólo II, Coimbra - Portugal

${ }^{2}$ AST-Active Space Technologies, Coimbra, Portugal
}

insulation and surface-dependent applications as catalysts, sensors, adsorbents [1-6]. In particular, the MTMS-derived aerogels exhibit very low bulk density $\left(\sim 50 \mathrm{~kg} / \mathrm{m}^{3}\right)$ and thermal conductivity $(\sim 0.036 \mathrm{~W} /(\mathrm{m} \mathrm{K}))$, high porosity $(95 \%)$ and surface area $(\sim 500$ $\left.\mathrm{m}^{2} / \mathrm{g}\right)$, moderate flexibility and hydrophobic character $\left(<140^{\circ}\right)[1]$.

Corresponding author: L. Durães, CIEPQPF, Department of Chemical Engineering, Faculty of Sciences and Technology, University of Coimbra, Pólo II, Rua Sílvio Lima, 3030-790 Coimbra - Portugal E-mail: luisa@eq.uc.pt 
The sol-gel synthesis of these silica based materials can be divided into three general steps: gel preparation, aging and drying of the gel. In the first step, a sol is prepared using a silicon source (precursor) and some equivalents of water that promote the hydrolysis and subsequent condensation of the precursor. By adjusting the $\mathrm{pH}$ with a catalyst, the cross-linking by polycondensation of the sol nanoparticles can be accelerated, leading to the formation of a 3-D nanostructured solid network with the solvent in the pores, i.e. the formation of a gel - gelation. After, the gel is aged in its mother solution. The aging process strengthens the gel network so that the pore shrinkage during the drying step may be kept to a minimum. Then, in the last step, the gel is dried to be freed of the pore liquid. To prevent the collapse of the gel, the conditions of this last step are critical and particular attention has been given to them.

Aerogels are obtained when the gel is dried at supercritical conditions and xerogels are produced by drying the gel at ambient pressure (solvent evaporation). Usually aerogels have higher porosities and surface areas and lower densities than xerogels, since the pore shrinkage that occurs in the evaporative drying, due to the capillary stresses developed by the receding of liquidgas interfaces, is avoided at supercritical conditions, and the porous structure of the gel solid phase may be kept almost intact during the aerogel formation $[7,8]$.

However, in the case of MTMS one alkoxy group of tetra-alkylorthosilicates is replaced by a methyl group - derivative group. This methyl group does not suffer hydrolysis and remains within the gel structure. Its presence increases the degree of disorder and the number of voids in the structure, leading to an increased porosity and making the aerogels flexible and hydrophobic. This hydrophobic character is of major importance to the drying stage, since due to the weak affinity/adhesion of the liquid (alcohol) to the solid, the capillary stresses are much less significant and the xerogels have properties very close to those of aerogels [1]. Thus, aerogel-like materials can be prepared by ambient pressure drying.

The more common method used to dry the gels at ambient pressure consists in making temperature cycles in an oven. In this work a different ambient pressure drying procedure was applied, using microwaves. The microwave drying, as it is called in this work, is an alternative ambient pressure drying technique that allows a fast fine drying stage and avoids the high temperature cycles of conventional evaporative drying performed in an oven. In microwave drying, the liquid molecules start to rotate and align their electric dipoles by means of the alternating electromagnetic field characteristic of the microwaves, causing an increase in the overall molecular vibration, i.e. promoting their own heating. The microwave drying process has some advantages when compared with evaporative drying in an oven, namely: i) the heat is generated internally within the material, promoting smaller thermal gradients and reducing cracking during the drying; ii) the drying time is reduced; iii) a reduction in energy consumption is also achieved [9]. In addition, microwave drying also allows to heat small and large pieces in a fast and uniform way $[9,10]$.

In this work, the properties of silica based aerogel-like materials obtained with two different ambient pressure drying methods are compared, namely the evaporative drying in a conventional oven and in a microwave oven. From our knowledge, it is the first time that microwaves are used to dry methyltrimethoxysilanederived gels. The drying time under the microwaves as well as the applied microwave power were changed to investigate their effect on the bulk density of the product. The material with the lowest density was then selected for comparison with the material dried in the oven. Thus, the aerogel-like materials obtained by these two drying procedures were characterized by several techniques, namely elemental analysis, Fourier transform infrared spectroscopy (FTIR), contact angle analysis, He picnometry, nitrogen gas adsorption, scanning electron microscopy (SEM) and thermal constants analysis, to assess and discuss their physical, chemical and structural properties.

\section{Experimental}

\subsection{Gels preparation}

Methyltrimethoxysilane $\left(\mathrm{CH}_{3} \mathrm{Si}\left(\mathrm{OCH}_{3}\right)_{3}, 98 \%\right.$, Aldrich), methanol $\left(\mathrm{CH}_{3} \mathrm{OH}, 99.8 \%\right.$, Riedel-de Haën), oxalic acid $\left(\mathrm{C}_{2} \mathrm{H}_{2} \mathrm{O}_{4}, 99 \%\right.$, Fluka) and ammonium hydroxide $\left(\mathrm{NH}_{4} \mathrm{OH}, 25 \%\right.$ in water, Fluka) were used as precursor, solvent, acid and basic catalysts, respectively. The catalysts were used in the form of acid an basic aqueous solutions of 0.01 and $10 \mathrm{M}$, respectively.

The used chemical synthesis procedure was first proposed by Rao and Bhagat [2, 3] and was already followed with success in earlier works of the authors $[1,4,5]$. In summary, the precursor is mixed with methanol and the oxalic acid solution, so the water of the acid solution promotes the hydrolysis reaction - acid step. One day after, the ammonium hydroxide solution is slowly added and the alkaline medium favors the condensation of silanols, increasing the reaction rate and forming a sol - basic step. These two steps are carried out at a controlled temperature of $25^{\circ} \mathrm{C}$ and the molar ratios of precursor:solvent:water are set at 1:35:8. After, the sol is placed in an oven at $27^{\circ} \mathrm{C}$ and gelation occurs within 4$5 \mathrm{~h}$. Finally, the gels were aged for two days at $27^{\circ} \mathrm{C}$.

\subsection{Drying of the gels}

After aging the gels, these are dried by two different ambient pressure drying procedures. The first consists in doing four drying cycles in an oven: $60^{\circ} \mathrm{C}$ during $24 \mathrm{~h}$, followed by three more cycles of $1 \mathrm{~h}$ each at $100^{\circ} \mathrm{C}, 150^{\circ} \mathrm{C}$ and $200^{\circ} \mathrm{C}$. The second uses microwaves and will be called from now on by microwave drying.

For the microwave drying, the first cycle described above is also applied, in order to remove the excess of methanol and give a more resistant gel to withstand the following step of solvent exchange. After the cycle at $60^{\circ} \mathrm{C}$, the gels are removed from the container and are washed with distilled water at $40^{\circ} \mathrm{C}$, in 10 batches. For this, a vacuum filtration system was used, being the gels placed in a Buckner funnel and water added to fill the funnel. Then, the vacuum in the underlying Erlenmeyer was generated by a vacuum pump in order to force the liquid to slowly pass through the filter. With these washing batches, the alcohol is progressively replaced by water and then the material is subjected to the microwave cycles. Three sets of conditions were tested for the 
Table 1. Bulk density and thermal conductivity of the obtained aerogel-like materials.

Tabelle 1. Dichte und thermische Leitfähigkeit der erhaltenen aerogelähnlichen Materialien.

\begin{tabular}{lll}
\hline Drying procedure & $\begin{array}{l}\text { Bulk density } \\
\left(\mathrm{kg} / \mathrm{m}^{3}\right)\end{array}$ & $\begin{array}{l}\text { Thermal conduc- } \\
\text { tivity }(\mathrm{W} /(\mathrm{m} \mathrm{K}))\end{array}$ \\
\hline Oven drying ${ }^{[a]}$ & $87.2 \pm 23.7$ & $0.042 \pm 0.001$ \\
Microwave drying (procedure 1) $^{[b]}$ & $91.3 \pm 26.9$ & $0.044 \pm 0.003$ \\
Microwave drying (procedure 2) $^{[b]}$ & $85.5 \pm 10.2$ & $0.042 \pm 0.007$ \\
Microwave drying (procedure 3) $^{[b]}$ & $76.4 \pm 10.5$ & $0.041 \pm 0.002$ \\
\hline
\end{tabular}

[a] Average results of 8 concordant syntheses.

[b] Average results of at least 3 concordant syntheses.

microwave drying, namely: 1) at $100 \mathrm{~W}$, repeating 5 times 3 minutes of continuous radiation followed by 1 minute of pause; 2) at $100 \mathrm{~W}$, repeating 3 times 5 minutes of continuous radiation followed by 1 minute of pause; 3) at $450 \mathrm{~W}$, repeating 3 times 2 minutes of continuous radiation followed by 2 minute of pause. After the microwave drying, the spring back effect on the gels occurs during two days at ambient temperature.

\subsection{Materials characterization}

In order to compare the properties of materials prepared with the different drying procedures, these materials were chemically, physically and structurally characterized using the following techniques:

Weight and volume measurements of regular pieces of material - to calculate the bulk density.

Thermal constants measurement (Thermal constants analyzer TPS 2500 S, Hot Disk) - to obtain the thermal conductivity of the samples. This analysis was carried out at $20^{\circ} \mathrm{C}$ and the used equipment has reproducibility better than $1 \%$ and accuracy better than $5 \%$.

Elemental analysis (EA 1108 CHNS-O, Fisons Inst.) - to obtain the $\mathrm{C}, \mathrm{H}, \mathrm{N}$ and $\mathrm{O}$ elemental composition of the samples, in order to verify the extent of condensation by the wt\% of $\mathrm{C}$ and to evaluate the amount of impurities. The determination of $\mathrm{C}, \mathrm{H}$, and $\mathrm{N}$ elements is made by the sample combustion with a stream of $\mathrm{He}$ enriched with $\mathrm{O}_{2}$, at $900^{\circ} \mathrm{C}$, and subsequent separation and detection of the combustion gases. To obtain the oxygen content, the sample is pyrolized and the evolved gases are evaluated.

Fourier transform infrared spectroscopy (FT/IR-4200, Jasco) to study the chemical structure of the aerogel-like materials. The sample was milled and mixed with $\mathrm{KBr}$ in a mass ratio of 1:100 and the resultant mixture was pressed in a mold to obtain thin circular pellets. These pellets were analyzed in a wave number range of $400-4000 \mathrm{~cm}^{-1}$.

Contact angle technique (OCA 20, Dataphysics) - to evaluate the hydrophobicity of the aerogel-like materials. Water drops are dropped in a flat surface of the sample and the angle which is enclosed between the baseline and a tangent to the drop contour at the three phase point (solid-liquid-gas) is evaluated (wetting angle).

He picnometry (Accupyc 1330, Micromeritics) - to measure the real (skeleton) density of the samples. Combining the information of the skeleton and bulk densities, it is possible to evaluate the porosity of the samples.
$\mathrm{N}_{2}$ gas adsorption (ASAP 2000, Micromeritics) - to obtain the surface area and the pore size distribution of the materials, using the BET and BJH-desorption theories, respectively.

Scanning electron microscopy (SEM) (JMS-5310, JOEL) - for the observation of the materials microstructure. Due to the low electrical conductivity of the highly porous silica-based samples, an Au film was deposited on their surface, using the Physical Vapor Deposition technique during $20 \mathrm{~s}$.

\section{Results and discussion}

\subsection{Selection of the best microwave cycles conditions}

In Table 1 are presented the bulk densities and thermal conductivities evaluated for the several types of aerogel-like materials obtained by the different ambient pressure drying procedures.

Before comparing the results between them, a comparison can be made between the bulk density obtained for the material dried in the oven and the earlier work results for the material synthesized with the same procedure - Xero-a in Ref. [1]. In fact, the only factor that has changed is the confinement of the gel, that now is a beaker $(60 \mathrm{~mm} \times 40 \mathrm{~mm})$ and in the earlier work was a test tube $(150 \mathrm{~mm} \times 15 \mathrm{~mm})$. The bulk density obtained in the test tubes was $78.4 \pm 10.5 \mathrm{~kg} / \mathrm{m}^{3}$ and it has now a higher value, as well as a higher variance. This may be due to the higher surface area for evaporation in the beaker, what makes the evaporation process faster and less controllable. Thus, the dimensions of the gel confinement seem to have a strong effect on the repeatability of the results.

When using the microwave drying, the results indicate that the best conditions are those applied in procedure 3, i.e., use of $450 \mathrm{~W}$, repeating 3 times 2 minutes of continuous microwave radiation followed by 2 minute of pause. These conditions lead to lower bulk density and thermal conductivity and also relatively low variance. Comparing the results of this sample and the sample dried in an oven, the first still is more promising for insulating purposes, since it has lower density and thermal conductivity (even when compared with results obtained in [1]).

In this way, the subsequent characterization was done for the material dried using the third procedure of microwave drying, and also for the material obtained by oven drying to allow a comparison with the conventional method. The appearances of these two kinds of samples are shown in Fig. 1, and they are very similar.

\subsection{Characterization of the chemical composition of the materials}

Table 2 shows the elemental analysis results and the contact angle values for the two selected samples, i.e., the sample dried in an oven and the sample dried by microwaves according to procedure 3.

Following the hypothesis of complete condensation of the three $\mathrm{OH}$ groups of the silanols, the expected mass percentage of the elements in the material structure would be $41.8 \mathrm{Si}: 17.9 \mathrm{C}$ : $4.5 \mathrm{H}: 35.8 \mathrm{O}$ (neglecting the $\mathrm{OH}$ groups at the structure ends) [1]. If the condensation is not complete, the mass percentage of carbon decreases to $15.8 \%$ [1], since the average number of oxygen 


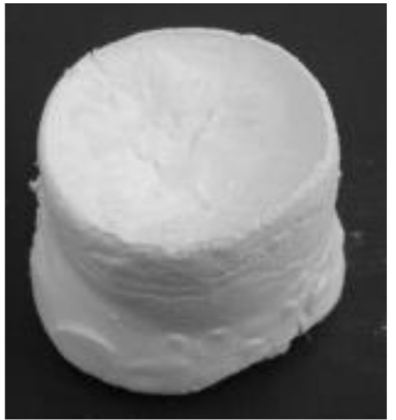

(a)

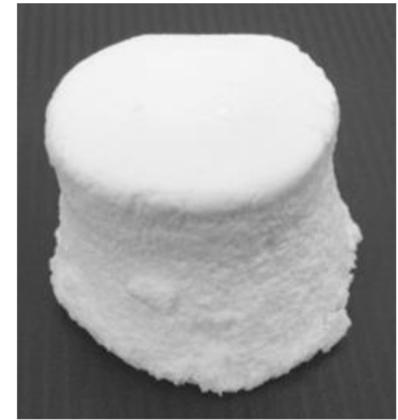

(b)
Figure 1. Typical appearance of the synthesized monoliths of aerogel-like materials: (a) dried in an oven; (b) dried using microwaves.

Bild 1. Typisches Erscheinungsbild der synthetisierten Monolithe von aerogelähnlichen Materialien: (a) in einem Ofen getrocknet, (b) mittels Mikrowellen getrocknet.

atoms per structural unit increases. Thus, by analyzing the results of $\mathrm{C}$ and $\mathrm{H}$ percentages, it can be concluded that the complete condensation/polycondensation hypothesis is valid, Table 2. The experimental values for oxygen are much lower than the expected value, but this happens because the used temperature in the elemental analysis furnace $\left(1060^{\circ} \mathrm{C}\right)$ is not enough to break the $\mathrm{Si}-\mathrm{O}$ bonds. Therefore, the experimental oxygen amount gives only an idea of the dehydration of the solid network (removing of the $\mathrm{OH}$ terminal groups). This may be variable but seems to have occurred in a higher extent in the sample dried using microwaves. The $\mathrm{N}$ amount leads to the conclusion that the impurities due to the presence of the basic catalyst are even lower than the obtained in the materials of an earlier work [1].

The observed contact angle values are typical of highly hydrophobic materials and this was expected due to the presence of methyl groups throughout the solid structure, Table 2 . The value obtained for the material dried in the oven is lower than that obtained for the material dried by microwaves. This may be due to the fact that in the microwave drying the temperature of the
Table 2. Elemental analysis results ${ }^{[a],[b]}$ and contact angle values ${ }^{[c]}$ for the synthesized aerogel-like materials.

Tabelle 2. Ergebnisse der Elementanalyse und Werte des Kontaktwinkels der synthetisierten aerogelähnlichen Materialien.

\begin{tabular}{llllll}
\hline & $\begin{array}{l}\mathrm{C} \\
(w t \%)\end{array}$ & $\begin{array}{l}\mathrm{H} \\
(w t \%)\end{array}$ & $\begin{array}{l}\mathrm{N} \\
(w t \%)\end{array}$ & $\begin{array}{l}\mathrm{O} \\
(w t \%)\end{array}$ & $\begin{array}{l}\text { Contact } \\
\text { angle }\left({ }^{\circ}\right)\end{array}$ \\
\hline Oven drying & 19.01 & 5.19 & 0.16 & 1.59 & $121.7 \pm 2.7$ \\
Microwave drying & 19.20 & 5.11 & 0.13 & 2.28 & $151.4 \pm 3.1$ \\
\hline
\end{tabular}

[a] The wt $\%$ errors associated with the measurements are $\pm 0.43, \pm 0.20$, \pm 0.25 and \pm 0.15 for $\mathrm{C}, \mathrm{H}, \mathrm{N}$ and $\mathrm{O}$, respectively.

[b] Average results of 3 concordant measurements.

[c] Average results of 10 concordant measurements.

sample is more uniform and not so high as the achieved in the oven. In this way, the possible degradation/decomposition of the methyl groups near the sample surface is minimized.

The FTIR spectra of the materials synthesized by both drying procedures are presented in Fig. 2. The assignment of the peaks is indicated in Table 3 and was based in the FTIR data for similar systems and for organic bonds. The chemical structure of both materials is nearly the same, except for the $\mathrm{OH}$ groups where the aerogel dried by microwaves shows a slightly different pattern. In this case, the $\mathrm{OH}$ sharp peak near $1630 \mathrm{~cm}^{-1}$ is imperceptible and the broad band above $3000 \mathrm{~cm}^{-1}$ has lower intensity and has shifted to the left, approaching the characteristic region of $\mathrm{OH}$ not linked by hydrogen bonds. This may indicate that the aerogel-like materials dried using microwaves have less $\mathrm{OH}$ groups on their surface. It can find explanation in the leaving of more $\mathrm{OH}$ groups during the microwave excitation, and this can be also a reason for the higher hydrophobicity observed in these materials when compared with those dried in the oven.

Globally, the FTIR spectra show evidence for the existence of a silica network (Si-O-Si) with the presence of Si-C and C-H bonds (hybrid structure), which are certainly due to the methyl groups attached to the silicon atoms. They also show O-H bonds that can be explained by the structural hydroxide groups of the network ends.

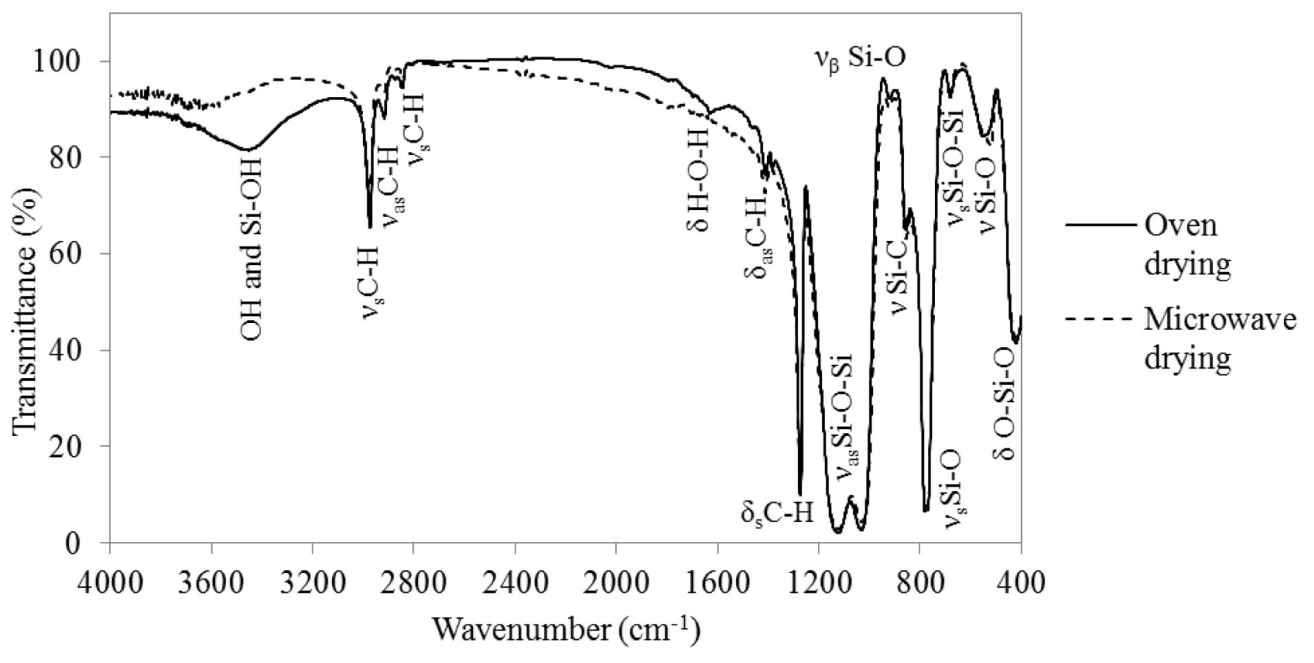

Figure 2. FTIR spectra for the materials dried in an oven and using microwaves.

Bild 2. FTIR Spektrum der in einem Ofen und durch Mikrowellen getrockneten Materialien. 


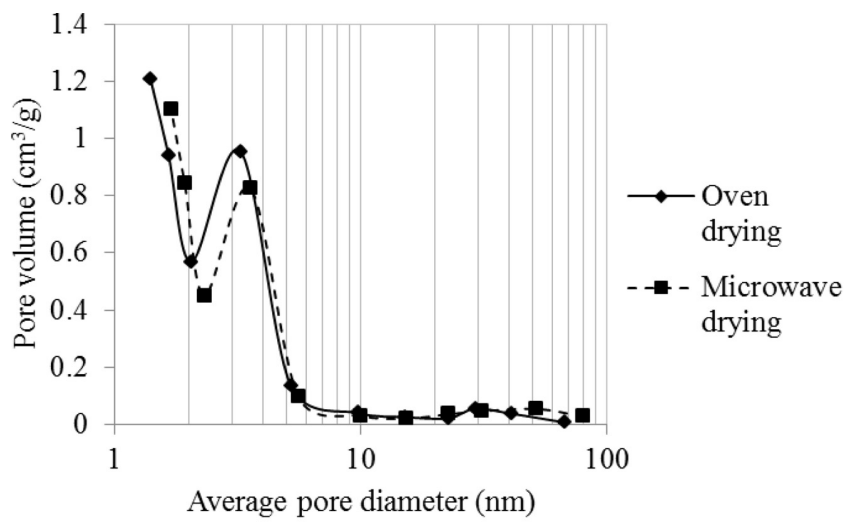

Figure 3. Pore size distribution of the aerogel-like materials dried in an oven and by microwaves.

Bild 3. Verteilung der Porengröße der in einem Ofen und durch Mikrowellen getrockneten aerogelähnlichen Materialien.

\subsection{Characterization of the microstructure of the materials}

In Table 4 are presented the results of specific surface area and average pore diameter of the aerogel-like materials. Type IV adsorption-desorption isotherms were obtained for both materials, with the characteristic hysteresis loop of mesoporous structures. The desorption branch was used to obtain the pore size distribution of the materials, Fig. 3. It can be concluded that the
Table 3. Position of FTIR peaks $\left(\mathrm{cm}^{-1}\right)$ for the aerogel-like materials and corresponding assignment to the type of vibration and chemical groups.

Tabelle 3. Lage des FTIR Peaks $\left(\mathrm{cm}^{-1}\right)$ für die aerogelähnlichen Materialien und entsprechende Zuweisung des Vibrationstyps und der chemischen Gruppe.

\begin{tabular}{|c|c|c|c|}
\hline $\begin{array}{l}\text { Oven } \\
\text { drying }\end{array}$ & $\begin{array}{l}\text { Microwave } \\
\text { drying }\end{array}$ & $\begin{array}{l}\text { Type of } \\
\text { vibration }^{[11,12][a]}\end{array}$ & Structural unit ${ }^{[11,12]}$ \\
\hline 421 & 417 & $\delta \mathrm{O}-\mathrm{Si}-\mathrm{O}$ & $\mathrm{O}-\mathrm{Si}-\mathrm{O}$ \\
\hline 552 & 520 & $v \mathrm{Si}-\mathrm{O}$ & $\mathrm{SiO}_{2}$ defects \\
\hline 680 & 680 & $v_{\mathrm{s}} \mathrm{Si}-\mathrm{O}-\mathrm{Si}$ & $\equiv \mathrm{Si}-\mathrm{O}-\mathrm{Si} \equiv$ \\
\hline 780 & 772 & $v_{\mathrm{s}} \mathrm{Si}-\mathrm{O}$ & $\equiv \mathrm{Si}-\mathrm{O}-\mathrm{Si} \equiv$ \\
\hline 854 & 854 & $v \mathrm{Si}-\mathrm{C}$ & Si-R \\
\hline 921 & 921 & $v_{B} \mathrm{Si}-\mathrm{O}$ & Free $\mathrm{Si}-\mathrm{O}^{-}$ \\
\hline 1032 & 1029 & $v_{\text {as }} \mathrm{Si}-\mathrm{O}-\mathrm{Si}$ & $\equiv \mathrm{Si}-\mathrm{O}-\mathrm{Si} \equiv$ \\
\hline 1123 & 1119 & $v_{\text {as }} \mathrm{Si}-\mathrm{O}-\mathrm{Si}$ & $\equiv \mathrm{Si}-\mathrm{O}-\mathrm{Si} \equiv$ \\
\hline 1273 & 1274 & $\delta_{\mathrm{s}} \mathrm{C}-\mathrm{H}$ & $\mathrm{Si}-\mathrm{R}$ \\
\hline 1410 & 1411 & $\delta_{\text {as }} \mathrm{C}-\mathrm{H}$ & Si-R \\
\hline 1631 & - & $\mathrm{d} \mathrm{H}-\mathrm{O}-\mathrm{H}$ & $\mathrm{H}-\mathrm{O}-\mathrm{H}$ \\
\hline 2846 & 2844 & $v_{\mathrm{s}} \mathrm{C}-\mathrm{H}$ & $-\mathrm{CH}_{2}$ \\
\hline 2917 & - & $v_{\text {as }} \mathrm{C}-\mathrm{H}$ & $-\mathrm{CH}_{2}$ \\
\hline 2973 & 2973 & $v_{\mathrm{s}} \mathrm{C}-\mathrm{H}$ & $-\mathrm{CH}_{3}$ \\
\hline 3453 & $\sim 3650$ & $\mathrm{O}-\mathrm{H}$ and $\mathrm{Si}-\mathrm{OH}$ & $\begin{array}{l}\mathrm{H}-\mathrm{O}-\mathrm{H} \ldots \mathrm{H}_{2} \mathrm{O} \text { and } \\
\equiv \mathrm{SiO}-\mathrm{H} \ldots \mathrm{H}_{2} \mathrm{O}\end{array}$ \\
\hline
\end{tabular}

[a] $v$ stretching vibration, $v_{\mathrm{s}}$ symmetric stretching vibration, $v_{\text {as }}$ anti-symmetric stretching vibration, $v_{\beta}$ in-plane stretching vibration, $\delta$ deformation vibration, $\delta_{\mathrm{s}}$ symmetric deformation vibration (bending), $\delta_{\text {as }}$ antisymmetric deformation vibration (bending).

materials dried in the oven have higher surface area than the materials obtained by microwave drying. This can be explained by lower average pore size in the first case. In fact, the pore size
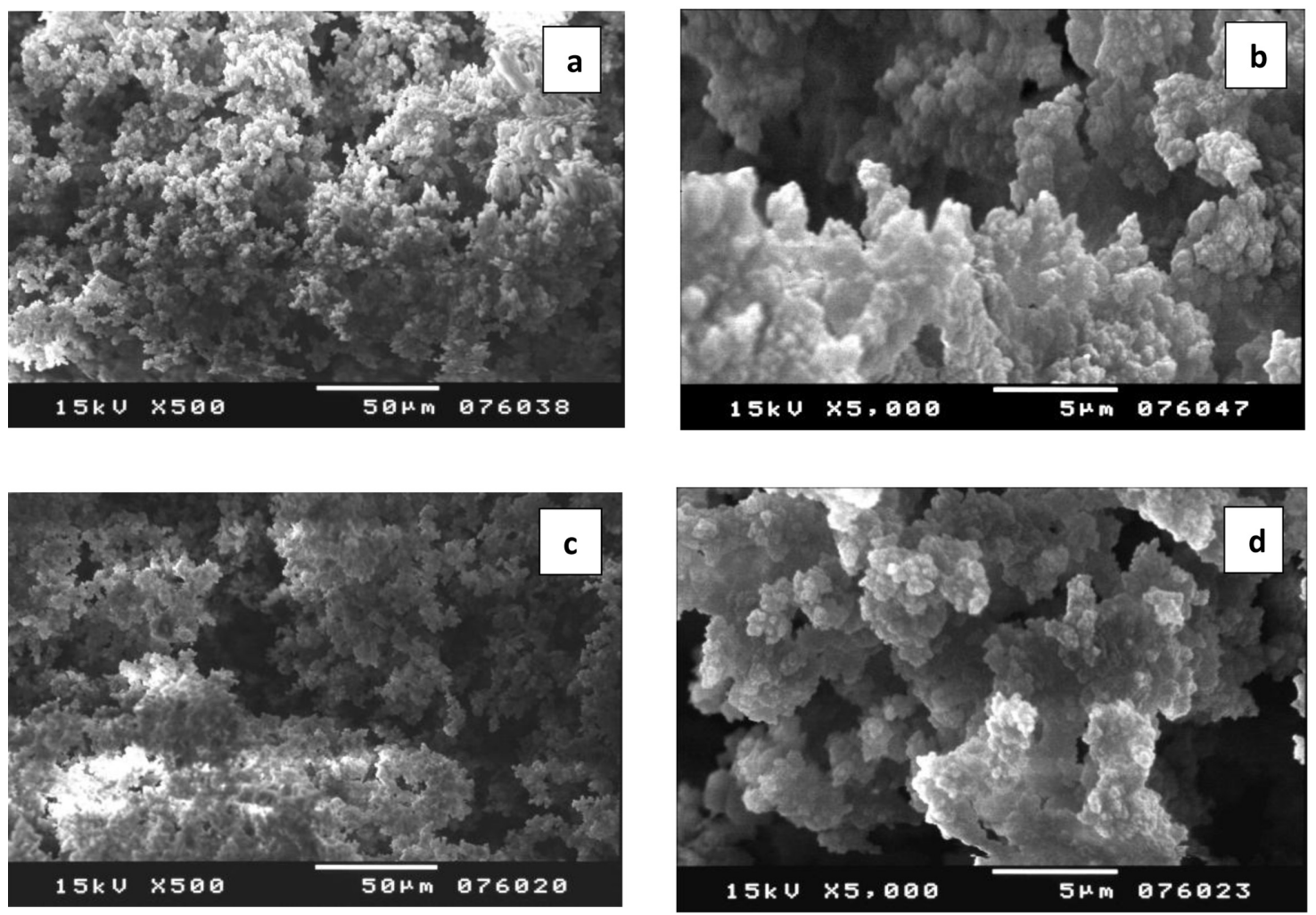

Figure 4. SEM images of the materials dried in an oven ( $a$ and $b$ ) and dried using microwaves (c and $d$ ).

Bild 4. REM Aufnahme der in einem Ofen ( $a$ und $b$ ) und mittels Mikrowellen ( $c$ und d) getrockneten Materialien. 
Table 4. Surface area, porosity and average pore diameter of the aerogel-like materials.

Tabelle 4. Oberfläche, Porosität und mittlerer Porenduchmesser der aerogelähnlichen Materialien.

\begin{tabular}{llll}
\hline Sample & $\begin{array}{l}\text { Specific surface } \\
\text { area }(B E T)^{[a]}\left(\mathrm{m}^{2} / \mathrm{g}\right)\end{array}$ & $\begin{array}{l}\text { Porosity } \\
(\%)\end{array}$ & $\begin{array}{l}\text { Average pore dia- } \\
\text { meter }(\mathrm{BJH})^{[\mathrm{b}]}(\AA)\end{array}$ \\
\hline $\begin{array}{l}\text { Oven drying } \\
\text { Microwave drying }\end{array}$ & $\begin{array}{l}579.3 \pm 14.2 \\
413.5 \pm 7.3\end{array}$ & 94.4 & 23.5 \\
\hline
\end{tabular}

[a] The correlation coefficient for the BET model fitting was at least 0.999 .

[b] Pores with diameter between 17 and $3000 \AA$.

distribution curve obtained for the aerogel-like material dried in the oven is partially shifted to lower pore diameters when compared to the curve of the material dried using microwaves. This reveals that the oven drying leads to more shrinkage of the pores, as already expected by the obtained values of the bulk density.

The porosity values for the selected materials are very close. They were evaluated using the bulk and skeleton densities of the materials. The skeleton densities were obtained by He picnometry and this technique presents another source of variability for the porosity results, thus the indicated values have only an indicative meaning.

SEM images of the materials microstructures are shown in Fig. 4. At lower magnification, the material dried in the oven has a more closed structure, as expected, but this is not evinced in the higher magnification images. The structural units of both materials are similar and have average size much less than $1 \mu \mathrm{m}$; the cross-linking of these primary units forms the continuous flaky structure, Fig. 4(b) and 4(d).

\section{Conclusions}

In this work, aerogel-like materials were obtained by microwave and oven drying of the gels synthetized with MTMS precursor by sol-gel technology. Three different procedures were tested in microwave drying. The best results were obtained when a power of $450 \mathrm{~W}$ was used, repeating 3 times, $2 \mathrm{~min}$. of continuous microwave radiation followed by $2 \mathrm{~min}$. of pause.

With microwave drying, the obtained materials had lower density and thermal conductivity when compared with those dried in an oven, making them more promising for insulating pur- poses. Moreover, the materials dried by microwaves showed higher hydrophobicity, what was confirmed by contact angle and FTIR results.

\section{Acknowledgements}

This work is funded by FEDER funds through the Operational Programme for Competitiveness Factors - COMPETE and National Funds, through FCT - Foundation for Science and Technology under the project PTDC/EQU-EPR/099998/2008 GelSpace - Silica Based Aerogels for Insulation of Spatial Devices.

\section{References}

[1] L. Durães, M. Ochoa, N. Rocha, R. Patrício, N. Duarte, V. Redondo, A. Portugal, J. Nanosci. Nanotechnol. 2012, 12, 6828.

[2] A. V. Rao, S. D. Bhagat, H. Hirashima, G. M. Pajonk, J. Colloid Interface Sci. 2006, 300, 279.

[3] S. D. Bhagat, C.-S. Oh, Y.-H. Kim, Y.-S. Ahn, J.-G. Yeo, Microporous Mesoporous Mater. 2007, 100, 350.

[4] L. Durães, M. Ochoa, A. Portugal, N. Duarte, J. P. Dias, N. Rocha, J. Hernandez, Adv. Sci. Technol. 2010, 63, 41.

[5] M. Ochoa, L. Durães, A. M. Beja, A. Portugal, J. Sol-Gel Sci. Technol. 2012, 61, 151.

[6] M. N. Perdigoto, R. C. Martins, N. Rocha, M. J. Quina, L. Gando-Ferreira, R. Patrício, L. Durães, J. Colloid Interface Sci. 2012, 380, 134.

[7] A. C. Pierre, G. Pajonk, Chem. Rev. 2002, 102, 4243.

[8] A. Soleimani Dorcheh, M. H. Abbasi, J. Mater. Process. Technol. 2008, 199, 10.

[9] G. Neves, R. Lenza, W. Vasconcelos, Mater. Res. 2002, 5, 447.

[10] S. Rajeshkumar, G. Anilkumar, S. Ananthakumar, K. Warrier, J. Porous Mater. 1998, 5, 59.

[11] R. Al-Oweini, H. El-Rassy, J. Mol. Struct. 2009, 354, 140.

[12] H. G. O. Becker, W. Berger, G. Domschke, E. Fanghänel, J. Faust, M. Fischer, F. Gentz, K. Gewald, R. Gluch, R. Mayer, K. Müller, D. Pavel, H. Schmidt, K. Schollberg, K. Schwetlick, E. Seiler, G. Zeppenfeld, Organikum, $2^{\text {nd }}$ ed., Fundação Calouste Gulbenkian, Lisboa, 1997.

Received in final form: January $30^{\text {th }} 2013$

$\mathrm{T} 140$ 